\title{
Integration of Eye Care into Primary Healthcare Tier in Nigeria Health System: A case for Delta State
}

\author{
John E Moyegbone ${ }^{1 *}$, Ezekiel U Nwose ${ }^{1,2}$, Samuel D Nwajei ${ }^{1}$, Emmanuel A Agege $^{1}$, Joseph O Odoko $^{1,3}$ and Eunice O Igumbor $^{1}$ \\ ${ }^{1}$ Department of Public and community Health, Novena University Ogume, Nigeria. \\ ${ }^{2}$ School of Community Health, Charles Sturt University, New South Wales, Australia. \\ ${ }^{3}$ Department of Community Health Science, Bayelsa State College of Health Technology, Otuogidi, Nigeria.
}

*Corresponding Author: John Moyegbone, Department of Public and Community Health, Novena University, Ogume, Nigeria. Tel: +2348062948357.

Received date: August 21, 2020: Accepted date: August 25, 2020: Published date: September 09, 2020

Citation: Moyegbone J.E, Nwose E.U, Nwanjei S.D, Agege E.A, Odoko J.O. and Igumbor E.O, (2020) Integration of eye care into primary healthcare tier in Nigeria health system: A case for Delta State J, Clinical Medical Reviews and Reports. 2(6); DOI:10.31579/2690-8794/038

Copyright: (C) 2020, John Moyegbone, This is an open access article distributed under the Creative Commons Attribution License, which permits unrestricted use, distribution, and reproduction in any medium, provided the original work is properly cited.

\section{Abstract}

Primary Eye Care (PEC) provides the essential cares of the eyes and visual pathways at the Primary Health Care (PHC) level in order to prevent avoidable visual impairment and blindness. The aim of this study is to review the need for integration of PEC services into PHC in Nigeria healthcare system - with focus oF Delta State. A narrative review approach was used in evaluation of community needs, government and PHC facilities. Published literatures from around the world including in Sub-Saharan Africa and Nigeria was done through web search and Mendeley reference library. The evaluations show that there is ability and willingness to integrate PEC into PHC. Yet, there is observable mismatch in capacity vs. opportunity or a knowledge and attitude gap. In Delta State on Nigeria, there appears to be specialist Eye-care providers located in just $24 \%$ of the local government areas and absolutely none (zero \%) at any PHC facility. In the rural communities, there is the barrier of affordances including problem of access, but the PHC staff can be equipped to provide basic services such as educational, preventive and referral services that non-governmental organisations have done. Therefore, integration of PEC into PHC at the community level is possible.

Keywords: primary eye care (PEC), primary health care (PHC), integration, government, community, health care workers

\section{Introduction}

The concept of primary healthcare (PHC) was propagated in 1978 in Alma-Ata declaration. PHC is the essential care made universally accessible to the community at a cost that the ordinary individuals can afford in their self-reliance and self-determination" [1]. PHC is the most efficient and cost-effective approach to achieve Universal Health Coverage [2]. PHC forms an integral part of the country's health system and a central point for social and economic development of every community. It is the first level of health service contact for individuals, families and communities and the national health system at large [3]. The
PHC system is a grass-root approach meant to address the main health problems in the community, by providing preventive, curative and rehabilitative services $[1,3]$. It is meant to provide services to the majority of the people based on needs without geographical, social or financial barriers through their involvement in the planning, implementation and evaluation of health programmes [1]. Primary eye care (PEC) is one of the 11 components of PHC to provide eye care at the grassroot level [4]. According to WHO, about 2.2 billion people are visually impaired (Figure 1); of which about $50 \%$ is either preventable or yet to be addressed [5]. For instance, it has been long known that cataract could be caused by trachoma infection, hence a mode of prevention is by clean water and good environmental sanitation [6].

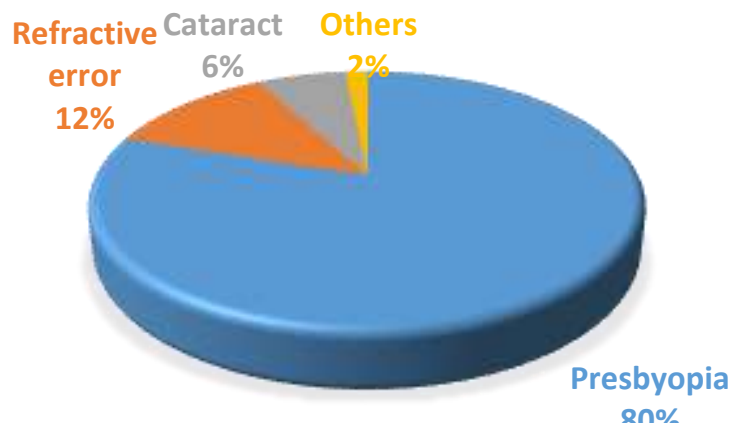

Figure 1: Distribution of visual impairments that are either preventable or yet to be addressed 
In Nigeria, PHC system is faced with barely functional facilities [3]. Inadequate availability of diagnostic equipment and general poor standard of care as well as lack of integration of significant aspects of health such as eye care into PHC is an issue [7]. It was documented that couching (a traditional method of treating cataract by dislocating the lens into the vitreous) accounts for almost half of all procedures for cataract despite the fact that this practice ultimately leads to blindness [8]. This practice may have proliferated due to weak PHC services and limited access to cataract surgical services at the grass root level of health care. It is recognized that PHC personnel including community health workers have knowledge of visual impairment, but PEC is still neglected [9]. Given the long-standing Vision 2020 program [6], the aim of this review is to evaluate the potential of PEC integration into PHC in order to minimize or prevent avoid visual loss in Delta State Nigeria.

\section{Method}

A narrative review approach was adopted. Over 75 published literatures on the subject were evaluated to assess PEC globally, Sub-Saharan Africa and in Nigeria. For the purpose of this review, selected literatures included mainly peer-reviewed journal articles and authoritative releases from the World Health Organization (WHO). The literatures were searched using the following key words: primary health care, primary eye care, health care workers in PHC, integration of primary eye care, role of government in PHC.

\section{Results}

\section{I: Evaluation of stakeholders}

\section{Government:}

There is very little information about governance in PEC- in policy setting or in implementation to ensure quality care, resulting to a high burden of visual impairment associated with lack of safety regulation, lack of awareness of prevention, and potentially harmful social norms of the community in low and middle-income countries [10]. Nigeria operates a three-tier federal system of government comprising the federal government, state and local governments [3]. National Health Policy prescribes a system in which PHC is under the purview of local governments, while the state and federal governments are responsible for the management of secondary and tertiary health care services respectively [11-13]. The National Primary Health Care Development Agency (NPHCDA) was charged with the responsibility to provides oversight for PHC [13]. The known prevalence of visual impairment in Nigeria (Fig 2), which was highlighted in the report of the survey conducted in 2005 - 2007 indicate variations across the geographical zones of the country $[14,15]$. It is plausible to that low level of blindness is a reason the government has yet give the much needed attention to eye care in terms of integrating PEC into PHC. For instance, a study reported nearly half of survey respondents with story of using eye glasses, only about one in twenty-five obtained their glasses from PHC [16]. A report from a recent audit of the Kwara Eye Health Programme showed that $40 \%$ of eye care facilities were unable to sustain services due to insufficient government support [17]. What probably needs to be emphasized is that there are moderate to severe grades of visual impairment, which add to clinical blindness to make the burden of eye healthcare quite a community health issue.

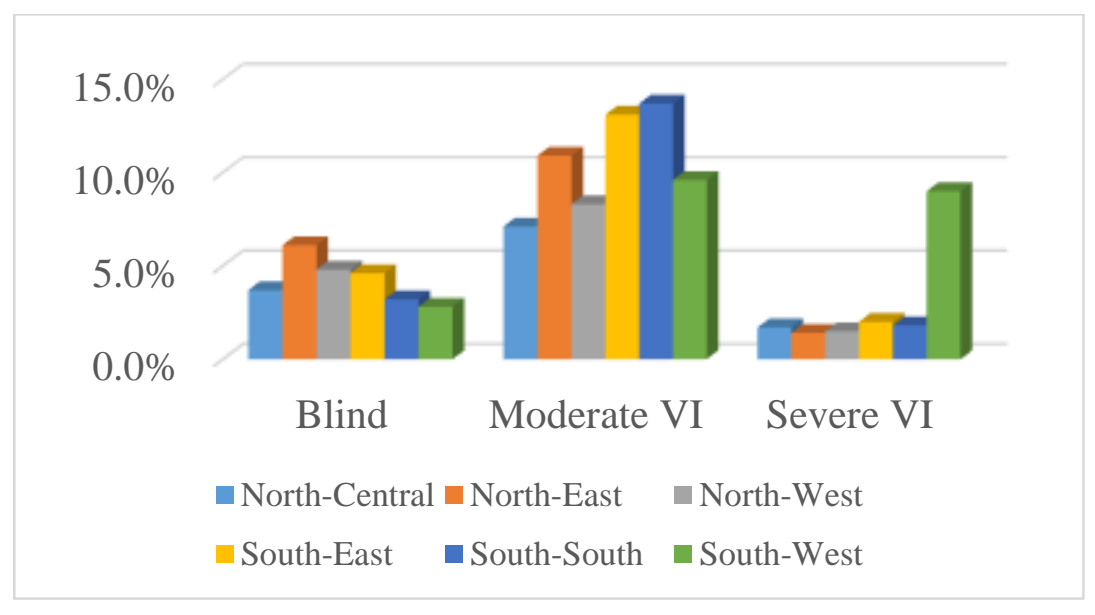

Figure 2: Prevalence of visual impairment in Nigerian survey of 2005 - 2007 [14]

Indeed, there has been the evidence in a community needs assessment report [10]. What this review evaluated is further evidence of knowledge and attitude vis-à-vis ability and willingness on the part of Nigerian government. Findings show that there is plans are underway to introduce primary eye care services in PHC across Nigeria, with intention to provide improved access for rural communities to eye care services. Part of the targeted outcome is for the people living with eye problems to quit harmful self-medication practices; and the implementation guideline will start with training of PHC workers on how best to administer PEC services to patients at rural communities [18]. Therefore, it can be said that there is knowledge of what to do and how to do it. However, how the plans are being implemented has yet to provide evidence whether they really want to do it or problem of supervision is the mitigating constraints [1]. It is worthy of note that in Nigeria health insurance scheme coverage is only about one percent ( $1 \%$ ) whereas up $27 \%$ incurs catastrophic health expenses [19], while inability to pay for PEC services has been reported as the most prominent barrier among the people [20]. Ghana NHIS established in 2003 covers over $95 \%$ of the most common disease conditions in its benefits package including eye care [10]. Hence a plausible recommendation has been for the government to consider a free package as acceptable healthcare service [7].

\section{Healthcare workers:}

Integrating eye health into PHC means these primary care workers will know how to prevent, detect and refer eye conditions at the level of PHC. The role of a PEC provider was outlined as the identification of those blind and vision impaired; assessment and diagnosis for referral; advice about referral and use of spectacles. Training of general PHC workers such as community health extension worker (CHEW), nurses, community health officers as well as lay persons such as traditional healers and school 
teachers on skills to assess eye condition is recommended for early detection and diagnosis of eye disorders at the community level [10].

Nigeria's health facilities both in urban and rural settlements lacks adequate eye care practitioners. There is estimated 3.3 ophthalmologists/million population, which while higher than the subSaharan regional average of 2.2, is less than the four recommended [17]. Nevertheless, the majority of ophthalmologists are concentrated in urban areas. For instance, study done in Enugu, South Eastern Nigeria, showed that there was not a single ophthalmologist, cataract surgeon or ophthalmic nurse working in either the public or private sector in Enugu State outside Enugu Urban metropolis [21]. Therefore, the greater number of Nigerians living in rural areas have to travel long distances to access eye care. Further implication is that in the absence of accessible orthodox eye care, patients are prone to access other sources such as patent medicine vendors, traditional healers and couchers due to proximity [8]. This barrier exacerbate the visual loss through harmful practices or delay appropriate treatment [17].Thus, there is evidence of missing opportunities to offer PEC in PHC even if the capacity/knowledge and motivation/plan are there.

\section{The community people:}

The increased rate of eye problems has been attributed to poor knowledge of patients in the communities, including on basic steps to take in situations of eye disorders $[18,20]$. This attribution is implied by the WHO as one the five recommendations is to raise awareness and empower people in the communities [5]. Community participation through awareness, and expectations of quality eye health care have resulted to remarkable reduction in visual loss. For instance, the 77\% reduction of onchocerciasis-induced blindness is due to community volunteers doing mass awareness [10]. This evidence that community members are receptive.

With regards to uptake of PEC services, there are various barriers including cost of eye care services predicated on cost of transportation, and lack of awareness of available services amongst others [20]. The knowledge of available eye care services and awareness of the different cadre of eye care professionals and service providers are important in utilisation of eye care facilities [22]. Level of awareness in the different regions of the country e.g. Sokoto State (Northern Nigeria) is higher than that of Cross River State (Southern Nigeria) with $80 \%$ and $47.1 \%$ respectively $[22,23]$. This variation in awareness may be as a result of compliant to Vision 2020 approach [23].

\section{II: Evaluation of PHC facilities services}

\section{Availability of need:}

Need to be addressed for both prevention and active management of eye diseases at PHC fall into three categories: health promotion, ensuring high coverage of specific preventive measures and the detection and referral of treatable eye conditions (eg, cataract, glaucoma) [16, 24, 25]. Eye health promotion is achieved through health education, especially on environmental hygiene, detecting visual disturbances early, eradication of myths and misconceptions on eye care. Eye health education also include advice on proper diet such as adding dark-green, leafy vegetables high in beta-carotene to the diet of young children, and increasing awareness on the availability of surgery to restore sight of those blind because of cataract, as well as other existing health services [25].

This is one area of need in eye health education for specific Preventive Measures: For example, in Tanzania, as measles immunisation coverage improved from approximately $30 \%$ to $80 \%$ between 1982 and 1988, the number of children admitted to a rural eye hospital with corneal ulcers associated with measles declined by $87 \%$ during the same period [24]. In Nigeria, there is lack of awareness of eye care service outlets [20,22], and this is technically a failure of PHC. In terms of knowledge and practice gap, it is indication of unmet community needs due PHC having limited practice in seeing and referring patients.

\section{Availability of services:}

Primary level public health activities such as vitamin A distribution, immunisation, and environmental hygiene program do make significant contributions to PEC services in PHC [10, 25]. Basic PEC involves eye health promotion, treatment of simple eye diseases, identification of persons needing specialist eye care followed by prompt referral $[16,25]$. PEC services needed for integration into PHC is shown in Table 1 below. Thus in Nigeria, the lack of PEC in PHC is evidence of capacityopportunity mismatch in the behavioural change wheel

\begin{tabular}{|l|l|}
\hline Element of PHC & Relation to Primary eye Care \\
\hline (Safe) water & Prevention of trachoma and cataract prevalence \\
\hline Basic sanitation & Prevention of trachoma and vitamin A deficiency \\
\hline Maternal and child care & Prevention of trachoma and ophthalmia neonatorum \\
\hline Immunisation (measles \& rubella) & Prevention of childhood blindness \\
\hline Control of locally endemic diseases & Trachoma control \\
\hline Health and nutrition education & Trachoma, vitamin A deficiency, trauma \\
\hline Treatment for common diseases & Corneal ulcers, refractive errors, trauma \\
\hline Provision of essential drugs & Tetracycline eye ointment and vitamin A capsules \\
\hline
\end{tabular}

Table 1: Integration of PEC in relation to the elements of PHC [25]

\section{Availability of material resources:}

Ophthalmic equipment such as Snellen charts, direct ophthalmoscope, penlight, retinoscope and eye drops (antibiotics) are basic material to be made available at PHC for early detection and treatment/referral of ocular disorders. Health personnel who provide eye care require appropriate infrastructure, equipment, equipment maintenance, an effective supply chain and technology to be able to provide quality eye care. Lack of equipment has been identified as a major influence on the productivity of 
eye care services. Study in Ethiopia, showed that after training health extension workers on trichiasis surgery intended to be integrated on routine activities, only about $3 \%$ of surgeons had all the essential items to perform trichiasis surgery [10]. If eye disorders are not detected early, treated and operated on with appropriate resources, late treatment can lead to amblyopia ('lazy eyes') and permanent visual loss, and delay in surgery and the duration of visual deprivation before surgery are associated with an exponential decline in visual acuity after surgery [24]. In Nigeria, evidence abound that human and material resources are the bane of PEC being lacking in rural communities and PHC [16, 20-22].

\section{Focus on Delta State}

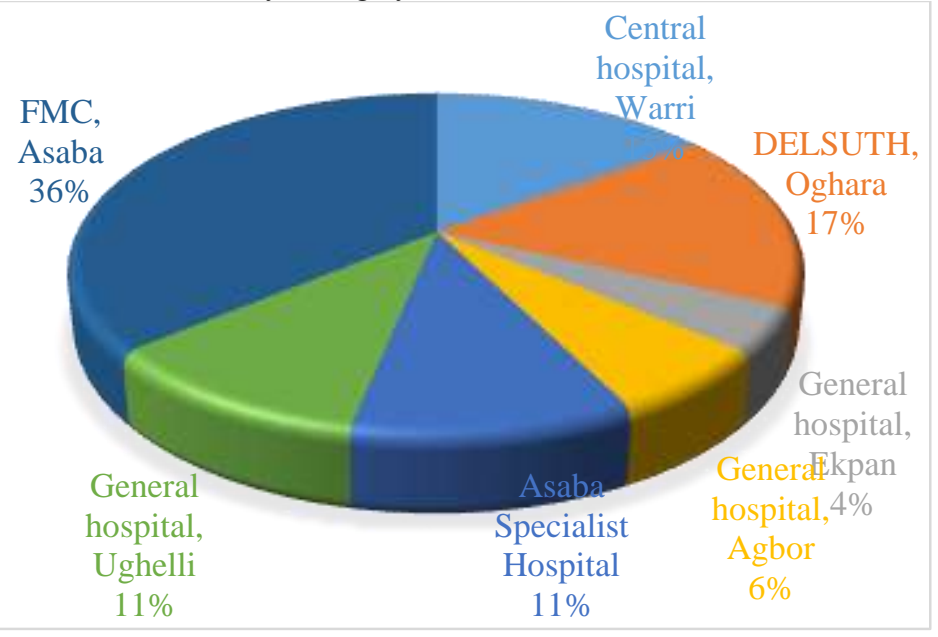

Figure. 3: Government hospitals with eye care unit and percentage of staff in Delta State

There was no available literature to show that Delta State Government have existing PEC program being integrated in PHC. Based on the researchers' observation on the state of PEC services, Delta State Government has approximately twelve (12) Ophthalmologists and twenty (25) Optometrists in the state civil service payroll. That is, 37 professional personnel to provide eye care services to the teeming population of over 5.6 million in the state. In the Delta state under focus, eye care services are provided in only 7 government hospitals including two tertiary hospitals being the Federal Medical Centre in state capital (FMC) and teaching hospital (DELSUTH) as shown in Figure 3.

These 7 hospitals that provide eye care services are located in just 6 out of the 25 Local Government Areas (LGA) in the state, and they are all located in the urban areas. There are no eye care services in the remaining nineteen (19) LGAs of the state. This also highlights that there is no PEC service at any PHC in the entire state.

Shortage of eye care practitioners is remarkable in the few government hospitals with eye care services. Table 2 shows the list of eye care provider in government hospitals in Delta State base on report from eye care practitioner in each facility. Although, the total number of Ophthalmologist and Optometrist in Nigeria may meet the minimum standard of 1:500,000 population recommended by WHO, the maldistribution of the eye care provider between the urban and rural settlements makes eye care services unavailable and inaccessibility in the grassroots level of the community [21].

\begin{tabular}{lcccc}
\hline & Ophthalmologist & Optometrist & Optician & Ophthalmic Nurse \\
\hline Central hospital, Warri & 1 & 2 & 1 & 3 \\
DELSUTH, Oghara & 2 & 3 & 1 & 2 \\
General hospital, Ekpan & 0 & 1 & 0 & 1 \\
General hospital, Agbor & 1 & 1 & 0 & 1 \\
Asaba Specialist Hospital & 1 & 1 & 1 & 2 \\
General hospital, Ughelli & 1 & 1 & 1 & 2 \\
FMC, Asaba & 4 & 3 & 4 & 6 \\
Total & 10 & 12 & 8 & 17 \\
\hline
\end{tabular}

Source: Verbal report from eye care practitioner in each facility 


\section{Discussion}

\section{Importance of PEC Integration into PHC}

As early as 1984, the World Health Organisation (WHO) advocated a PHC approach to increase access to eye care [26]. PEC is an integrated, participatory and inclusive approach to the eye health component of PHC consisting of promotive, preventive, curative and rehabilitative services $[4,10,25]$. It is targeted not only towards preventing blindness and visual impairment, but also towards providing services to redress ocular morbidity at the grassroots level of the community. PEC delivery uses the horizontal integration matrix model proposed by the World Health Organization to incorporate PEC programmes into the existing PHC structure to directly or indirectly provide eye care services related to promotion, protection, and improvement of population eye health [25].

Following the limited number of eye care professionals available to serve the overwhelming population, only few people residing within the urban settlement that can find their way to queue up as early as 5:00 am will usually be attended to in the few government hospitals with eye care services [20]. Others that could not come as early as possible to queue up, especially those residing far away in the rural communities do not have access to eye care in the government hospital. And those that cannot afford the cost of eye care services in private eye clinic will be left with no other option than to seek alternative traditional medicine or selfmedication that will end up resulting in visual impairment or blindness $[16,20]$. Integration of eye care services and employment of qualified eye care practitioners into the PHC will automatically create accessibility, affordability and availability of eye care services to the people at the community level thereby preventing avoidable blindness and reducing the magnitude of visual impairment to the barest minimum, and hence increase productivity of the individual as well as relief the psychological burden on the visually impaired and their dependants [10,24].

\section{Roles of Non-Governmental Organizations (NGOs) on PEC in Nigeria}

The good work of several NGOs such as Sight Savers and CBM (Centre for Blind Mission), carrying out cataract, glaucoma, trichiasis and other eye surgeries in rural communities using PHC centres in most cases have ameliorated the burden of visual impairment in Nigeria. The broad aim of the Sight savers-supported programme was to reduce preventable blindness through the provision of sustainable outreach, primary and secondary referral services using a health systems' strengthening approach [17]. The PEC programme which covered all the districts in Sokoto, Kwara, Kaduna and Zamfara states, with at least one eye clinic providing eye care services for a cluster of districts markedly reduced the prevalence of visual impairment in the states [17, 23]. An evaluation of the Sokoto eye-care programme shows that although the prevalence of unoperated cataract remains high, there has been a sevenfold increase in cataract surgical coverage (the proportion of people who have received cataract surgery as a percentage of all those who could have benefited from cataract surgery) and a doubling of the cataract surgical rate (the number of cataract operations performed per million population/year) since the inception of the programme. In Kaduna state, Sight savers achieved its target of providing services in at least $70 \%$ of districts. However, the failure of the programme to maintain a skilled workforce at the primary level has affected sustainability. A major limitation of the NGO-led initiatives in PEC in Nigeria, is lack of resources to sustain funding. Increasing access to eye-care is a challenge that need to be overcome not by the NGO sector alone, but by active involvement of the tiers of government in collaboration with various stakeholders in eye care sector on how eye health services and policies are planned, coordinated and implemented at all levels [13, 17, 23]

\section{Conclusion}

The benefit of PEC as an integral component of the continuum of care is potentially enormous in terms of preventing avoidable visual impairment and increasing access to special education and rehabilitation services. PEC, therefore, includes many activities which can be implemented in the community, or at the primary level of health care. PEC is the essential building block for prevention of blindness in all communities and in all regions of the world. Integration of the eye care into PHC in Nigeria is a significant step forward in health care delivery. This evaluation report highlights that there is mismatch in the behavioural change wheel of the health providers. In particular, there is indication of knowledge of what to do and how to do it, but the intention or plan are yet to be actioned in order to demonstrate the willingness.

\section{Acknowledgments}

We are thankful to the Head of Department, Public and Community Health, Novena University, Ogume, Delta State, Nigeria and all the lecturers and staffs who supported us in every stage of the study.

Funding: This study was not funded by any organization.

Conflict of interest: There was no conflict of interest to declare.

\section{References}

1 Alenoghena, I., Aigbiremolen, A., Abejegah, C. \& Eboreime, E. (2014). Primary Health Care in Nigeria: Strategies and constraints in implementation. International Journal of Community Research 3, 74-79.

2 Welcome, M. O. (2011). The Nigerian health care system: Need for integrating adequate medical intelligence and surveillance systems. J Pharm Bioallied Sci 3, 470-478.

3 Uzochukwu, B. S. Ughasoro, M. D., Etiaba, E., Okwuosa, C., Envuladu, E., \& Onwujekwe, O. E. (2015). Health care financing in Nigeria: Implications for achieving universal health coverage. Niger J Clin Pract, 18(4), 437-444.

4 Khan, M. A., Soni, M. \& Khan, M. D. (1998). Development of primary eye care as an integrated part of comprehensive health care. Community eye health 11, 24-26.

5 World Health Organization. (2019). World report on vision. $C C$ BY-NC-SA 3.0 IGO licence, WHO/NMH/NVI/19.13.

6 Courtright, P. \& Bassett, K. (2003). Gender and blindness: eye disease and the use of eye care services. Community eye health 16, 11-12.

7 Aregbeshola, B. S. \& Khan, S. M. (2017). Primary health care in Nigeria: 24 years after Olikoye Ransome-Kuti's leadership. Frontiers in public health $\mathbf{5}, 48$.

8 Gilbert, C. E. Murthy, G. V., Sivasubramaniam, S., Kyari, F., Imam, A., Rabiu, M. M., . . . Tafida, A. (2010). Couching in Nigeria: prevalence, risk factors and visual acuity outcomes. Ophthalmic Epidemiol, 17(5), 269-275.

9 AbdulRahman, A. A., Rabiu, M. M. \& Alhassan, M. B. (2015). Knowledge and practice of primary eye care among primary healthcare workers in northern Nigeria. Trop Med Int Health 20, 766-772.

10 du Toit, R. ., Faal, H. B., Etya'ale, D., Wiafe, B., Mason, I., Graham, R., et al. (2013). Evidence for integrating eye health into primary health care in Africa: a health systems strengthening approach. BMC Health Serv Res, 13, 102.

11 Eboreime, E. A., Nxumalo, N., Ramaswamy, R. \& Eyles, J. (2018). Strengthening decentralized primary healthcare planning in Nigeria using a quality improvement model: how contexts and 
actors affect implementation. Health policy and planning 33, 715-728.

12 Onwujekwe, O., Hanson, K., Ichoku, H. \& Uzochukwu, B. (2014). Financing incidence analysis of household out-of-pocket spending for healthcare: getting more health for money in Nigeria? The International journal of health planning and management 29, e174-185, doi:10.1002/hpm.2166.

13 Uzochukwu, B. S. C. (2017). Primary health care systems (PRIMASYS): Case study from Nigeria.

14 Kyari, F. , Gudlavalleti, M. V. S., Sivsubramaniam, S., Gilbert, C. E., Abdull, M. M., Entekume, G., et al. (2009). Prevalence of blindness and visual impairment in Nigeria: The National Blindness and Visual Impairment Survey. Investigative Ophthalmology \& Visual Science, 50(5), 2033-2039.

15 Dineen, B., Gilbert, C. E., Rabiu, M., Kyari, F., Mahdi, A. M., Abubakar, T., et al. (2008). The Nigerian national blindness and visual impairment survey: Rationale, objectives and detailed methodology. BMC ophthalmology, 8(1), 17.

16 Ndep, A. O, Ekpenyong, B. N., Okareh, O. T., Peter, A. H., Ezenwankwo, A., \& Ayuk, F. N. (2017). Eye care seeking behaviours of patients in rural Cross River State, Nigeria. Research on humanities and social sciences, 7(2), 11-15.

17 Aghaji, A. E., Gilbert, C., Ihebuzor, N. \& Faal, H. (2018). Strengths, challenges and opportunities of implementing primary eye care in Nigeria. BMJ global health 3, e000846.

18 Ezeh, F. (2019). FG to integrate primary eye care into PHC services.
19 Onwujekwe, O., Hanson, K. \& Uzochukwu, B. (2012). Examining inequities in incidence of catastrophic health expenditures on different healthcare services and health facilities in Nigeria. PloS one 7, e40811-e40811.

20 Okoye, R. S., Bell, L. \& Papadopoulos, I. (2018). Barriers to accessing good eye care services in Nigeria: A focus on Anambra State. Journal of the Nigerian Optometric Association 20, 30 - 37.

21 Eze, B. I. \& Maduka-Okafor, F. C. (2009). An assessment of the eye care workforce in Enugu State, south-eastern Nigeria. Hum Resour Health 7, 38.

22 Etim, B. A, Ibanga, A. A., Udoh, M.-M. E., Okonkwo, S. N., Agweye, C. T., Utam, U. A., \& Eni, E. N. (2018). Eye care cadre utilization and knowledge about Eye Care Professionals among university students in Calabar, Nigeria. Journal of Advances in Medicine and Medical Research, 28(2), 1 - 6.

23 Muhammad, N. \& Adamu, M. D. (2014). Making a difference with Vision 2020: The Right to Sight? Lessons from two states of North Western Nigeria. Nigerian journal of clinical practice 17, 723-728.

24 Malik, A. N. J., Mafwiri, M. \& Gilbert, C. (2018). Integrating primary eye care into global child health policies. Archives of disease in childhood 103, 176-180.

25 Konyama, K. (1998) Essential components of primary eye care. Community eye health 11, 19-21.

26 World Health Organization. (1997). Strategies for the prevention of blindness in national programmes: a primary health care approach.

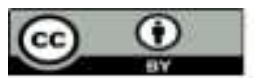

This work is licensed under Creative Commons Attribution 4.0 License

To Submit Your Article Click Here: Submit Article

DOI: $10.31579 / 2690-8794 / 039$
Ready to submit your research? Choose Auctores and benefit from:

* fast, convenient online submission

* rigorous peer review by experienced research in your field

* rapid publication on acceptance

* authors retain copyrights

* unique DOI for all articles

* immediate, unrestricted online access

At Auctores, research is always in progress.

Learn more www.auctoresonline.org/journals/clinical-medical-reviewsand-reports 